\title{
Training Needs Of Rice Farmers In Mahanawiyah District, AL-Qadisiya Province, Iraq
}

\section{Bassim Kshash*}

Agriculture College, Al-Qasim Green University, Babylon, Iraq

\section{A R T I C LE IN F O}

\section{Article history:}

Received 29 March 2016

Accepted 14 November 2016

Available online, ISSN: 2148-127X

Keywords:

Training

Need assessment

Rice cultivation

Rice farmers

Iraq \begin{abstract}
A B S T R A C T
The study was conducted in Mahanawiyah district in AL-Qadisiya Province, Iraq to identify the training needs of rice farmers. 125 farmers were selected as a random sample. A list of 8 major areas of training needs in relation to rice cultivation practices was prepared whiten 50 sub-area. Scores were measured on four-point scale. The primary data were collected using a pre-tested structured interview schedule by conducting personal interview. Findings revealed that majority of the farmers had medium level of training needs. Weed management, disease and pests control, seed and seedling were the top most training needs of the farmers and the least training need was Land preparation. The variables educational attainment, area cultivated with rice, and annual revenue from rice cultivation had positive and significant association with the training needs.
\end{abstract}

${ }^{*}$ Corresponding Author:

E-mail: bassimhaleem@yahoo.com

\section{Introduction}

Rice (Oryzae sativa) is the fundamental principle food for about half of the world's population. In Iraq rice is the most important summer crop. It comes in third place after wheat and barley in terms of area planted and production for 2015 .The area under rice cultivation was 27608 hectare producing 109209 tons of paddy, with an average yield 3.96 Mt.ha $^{-1}$, its cultivation concentrated in the Middle Euphrates provinces especially AL-Qadisiyah which come first in terms of planted area (16094 hectare) and production (56563 tons), (SCO, 2016).

Rice productivity in Iraq is $3.96 \mathrm{Mt}^{-h^{-1}}$, very low compared with Egypt (9.5 Mt.ha ${ }^{-1}$ ), Morocco (7.5 Mt.ha ${ }^{-1}$ ), (AOAD, 2015), China (6.7 Mt.ha ${ }^{-1}$ ), USA (8.3 Mt.ha $\left.{ }^{-1}\right)$, (Mundhe, 2015) and Uruguay (8 Mt.ha ${ }^{-1}$ ), (Tarlera et al., 2016). The low yield is mainly due to several reasons, and the most important is mismanagement of rice farmers to their farms.

Improve skills of rice growers in managing their farms is through training that aimed to providing them with the necessary skills. Training plays a very important role for human resource development.

It is generally assumed that agricultural education and training has a major role as a creator of capacity and supplier of the human resources necessary to increase agricultural productivity and sustainability of farming systems (Gina and Madsen, 2013). Training is mostly directed at improving the ability of individuals to do vocation more effectively and efficiently. Generally, it involves acquiring information, knowledge and developing abilities or attitudes, which will result in greater competence in the performance of a work (Tsado et al., 2014). In order to make any training meaningful and effective, it is imperative on the part of the training organizers to identify the training needs of the farmers based on which a suitable training module can be developed so that the appropriate training is given and higher degree of productivity and profitability can be achieved (Chawang and Jha, 2010). Training needs assessment is the first step that must be taken in designing the educational and training programs and agricultural extension, and the process has its own principles and specific methods required to achieve it (Ansari, 2006).

Understanding rice farmers' training needs helps in designing appropriate policies and extension programs which could contribute to improving the skills and expertise of rice growers and increase productivity. Many studies have been conducted for this purpose in different regions of the world, such as (Bajpai et al., 2007; Chawang and Jah, 2010; Nath and Chowdhury, 2010; Devarani, 2013) in India, (Tologbonse et al., 2008; Alarima et al., 2011; Tsado et al., 2014) in Nigeria, (Nahfees, 2013) in Sri Lanka, (Goli et al., 2013) in Iran, 
(Benard et al., 2014) in Tanzania. These studies indicate that the major areas of training needs of the rice growers were: plant protection measures, fertilizer management, loan and intercultural operation, winnowing, threshing, insect and disease management, water management, weed management, land preparation, sowing and transplanting, harvesting and storage, surface leveling and smoothening, nursery management, selection of high yielding varieties, selection of healthy seeds, marketing. .

In order to promote the level of expertise and skills of rice farmers in Iraq and increase production and productivity of rice crop, we need to study the training needs of rice farmers especially when we know the lack of such studies in this topic.

\section{Study Objectives}

The general objective of the study was to determine the training needs of rice farmers in Mahanawiyah district, Qadisiyah Province, Iraq. The specific objectives of the study were to;

- Identify training needs of rice farmers in Mahanawiyah district, Qadisiyah Province in some aspects of rice cultivation.

- Study the correlation between some characteristics of rice farmers (age, educational attainment, area cultivated with rice, years of experience in rice cultivation, umber of training courses, and annual revenue from rice) and training needs.

- See if there are significant differences between the respondents in their training needs depending on their characteristics.

\section{Material and Methods}

The study was carried out in Mahanawiyah district, AL- Qadisiyah Province, Iraq. The population for this study consisted of 400 paddy growers in the district, 10 of them were chosen for testing the questionnaire reliability. From the 390.12 were selected at random. The instrument used was a 2 part questionnaire. The first included the socio-economic characteristics: age, educational attainment, area cultivated with rice, years of experience in rice cultivation, umber of training courses, annual revenue from rice (see table 5).The second part included 8 aspects of rice cultivation practices with 50 sub-aspects: land preparation(6 sub-aspects), seed and seedlings (13), water management (4), weed management (7), fertilization (5), disease and pests control (7), harvesting and post harvesting (5), marketing (3).
Content validity of the questionnaire was established by a panel of experts in the field of agricultural extension and rice cultivation. A pilot study was conducted to establish reliability of the instrument, a Cronbach's alpha (a reliability coefficient) of 0.90 was established, indicating the instrument used was reliable and valid.

For each of the 50 sub-aspects, respondents were told to use a 4 Likert-like scale representing the training needs where: (4) represent very highly needed, (3) highly needed, (2) moderately needed, (1) slightly needed.

Face to face interviews were used and data collected by researcher visits to respondents during 5 - 22 October, 2014. Data were analyzed using frequency, percentage, weighted arithmetic mean, simple correlation and Chisquare test. Based on alternatives answers placed of each of the 50 sup aspects a 1- 4 numeric values were used. Respondents were classified into 3 categories according to total score including level of training needs: low (5099), medium (100-149) and high (150-200). For the 8 main aspects and 50 sub-aspects classification was based on need level as: low (1-1.9), medium (2-2.9), and high (3-4). Farmer's training need of aspects and sup-aspects of rice cultivation practices was analyzed separately, weighted mean score were calculated, the relative importance was ranked in descending order.

\section{Results and Discussions}

\section{First}

The distribution of respondents based on their level of training needs in some area of rice cultivation is shown in Table 1. Majority of the respondents $(51.2 \%)$ belonged to 'medium' category followed by $(35.2 \%)$ and $(13.6 \%)$ in 'high' and 'low' categories of training needs in some area of rice cultivation respectively. The average needs for training for all respondents were (135.47) which are within medium level of range of values between $50-200$.

As for the respondents need for training in some aspect of rice cultivation, Table 2 indicates that weed management be in first ranked in terms of the level of need training with an average (3.5), followed by Disease and pests control (3.33), Seed and seedling (3.18), fertilization (2.72), marketing (2.17), water management (1.95), harvesting and post harvesting (1.81) and land preparation (1.56). This means that areas of weed management, disease and pests control, seed and seedling were a high level of need for training, while areas of water management, harvesting and post harvesting and Land preparation were a low level of need for training.

Table 1 Distribution of respondents according to their training needs in some aspects of rice cultivation $(\mathrm{N}=125)$

\begin{tabular}{l|cccc}
\hline \multicolumn{1}{c|}{ Level of training needs } & Score rang & $\mathrm{n}$ & $\%$ & Average training needs \\
\hline Low & $50-99$ & 17 & 13.6 & 135.47 \\
Medium & $100-149$ & 64 & 51.2 & \\
High & $150-200$ & 44 & 35.2 & \\
\hline Total & & 125 & 100 & \\
\hline Source: Field Survey Data, 2014 & &
\end{tabular}


Table 2 Categories and average need for training in each aspects of rice cultivation

\begin{tabular}{|c|c|c|c|c|c|c|c|}
\hline \multirow{3}{*}{ Areas } & \multicolumn{7}{|c|}{ Need category } \\
\hline & \multicolumn{2}{|c|}{ Low } & \multicolumn{2}{|c|}{ Medium } & \multicolumn{2}{|c|}{ High } & \multirow{2}{*}{$\begin{array}{c}\text { Average } \\
\text { need }\end{array}$} \\
\hline & $\mathrm{n}$ & $\%$ & $\mathrm{n}$ & $\%$ & $\mathrm{n}$ & $\%$ & \\
\hline Weed management & - & - & - & - & 125 & 100 & 3.50 \\
\hline Disease and pests control & - & - & 18 & 14.4 & 107 & 85.6 & 3.33 \\
\hline Seed and seedling & - & - & 40 & 32.0 & 85 & 68.0 & 3.18 \\
\hline Fertilization & 19 & 15.2 & 56 & 44.8 & 50 & 40.0 & 2.72 \\
\hline Marketing & 60 & 48.0 & 41 & 32.8 & 24 & 19.2 & 2.17 \\
\hline Water management & 88 & 70.4 & 12 & 9.6 & 25 & 20.0 & 1.95 \\
\hline Harvesting and post harvesting & 85 & 68.0 & 35 & 28.0 & 5 & 4.0 & 1.81 \\
\hline Land preparation & 111 & 88.8 & 14 & 11.2 & - & - & 1.56 \\
\hline
\end{tabular}

As for the sub- aspect of rice cultivation, results in Table 3 shows that there are 22 sub-aspect of high need for training, which is correct way of planting seedlings in the field (3.88), appropriate time for application of pesticides (3.87), collecting of seedlings (3.86), age of the seedlings for transplanting (3.85), biological weed control (3.81), understanding the disease symptoms of rice(3.76), knowledge of preventive culture and mechanical practices(3.72), identification of effective factors in rice disease spread (3.65), knowledge of cultivation and mechanical practices to preventing weeds (3.61), Preparation of nursery (3.54), appropriate time for application of herbicide (3.50), method use and doses of herbicide (3.38), method of application and doses of pesticides (3.33), method of seed treatment (3.31), identification of rice weed (3.30), optimum time of sowing (3.21), prepare the ground for planting seedlings (3.19), knowledge of soil testing (3.19), knowledge of chemical herbicide (3.18), method of sowing (3.17), knowledge about the nutrient content of fertilizer (3.08), identification of diseases and their control measures (3.00). There is an 18 sub-aspect with medium need for training and 10 with a low need.

Second: The relationship between socio-economic characteristics of rice farmers and their need for training

It was evident from Table 4 that educational attainment , area cultivated with rice, and annual revenue from rice cultivation had positive and significant correlation with training needs at 0.05 level of probability, the values of simple correlation coefficient was $(0.360$, $0.225,0.374)$ respectively ,this means that training needs increased by increasing education, area and revenue, it can be further explained that educated farmers need more training in relation to rice cultivation practices, this due to the fact that more educated farmers are aware about the importance of training and they want to learn skills involved in advanced vegetable cultivation .On the contrary of years of experience in rice cultivation which had negative and significant association. Moreover, age and participate in training courses in rice cultivation were found to be non-significant.

\section{Third}

The difference in training needs depending on the characteristics of respondents Chi square analysis was used to see whether there is a difference between the level of the training needs of respondents, depending on their characteristics, from Table 5 it is clear that is no significant difference between training needs of respondents depending on age and years of experience in rice cultivation, while there is a significant difference depending on educational attainment, area cultivated with rice, participate in training courses in rice cultivation and annual revenue from rice cultivation. The results show (Table 5) that the highest proportion of respondents with the high need for training were among the first category of training courses (28\%), followed by third category of educational attainment $(17.6 \%)$. While the highest percentage of respondents at least need for training within the first category of educational attainment and second category of training courses $(8 \%)$.

\section{Conclusion}

It may be concluded that majority $(51.2 \%)$ of the respondents in Mahanawiyah district had medium level of training need in some rice cultivation practices .Most important training need aspect was weed management, disease and pests control, seed and seedling. Regarding weed management farmers wanted knowledge about preventive culture and mechanical practices.

Educational attainments had a positive and significant relationship with training needs, it means, as the education level of the farmers increased, the training needs also increased, It is due to the fact that more educated farmers are aware about the importance of training and they want to learn skills and practices involved in advanced rice cultivation. The same relationship found between area cultivated with rice, annual revenue from rice cultivation and training needs. There are a significant differences between the respondents in terms of training needs depending on educational attainment, area cultivated with rice, participate in training courses in rice cultivation and annual revenue from rice cultivation. Farmers ho not participate in any training course represented the highest proportion $(28 \%)$ of respondents with the high need for training. 
Table 3 Weighted mean for training needs of sub-aspects for some rice cultivation practices

\begin{tabular}{|c|c|c|}
\hline Aspect & Sub - aspects & $\mathrm{We}$ \\
\hline \multirow{6}{*}{ Land preparation } & Time for land preparation & 1.00 \\
\hline & Correct time to start ploughing & 1.10 \\
\hline & Puddling & 1.16 \\
\hline & Use of tillage equipment & 1.32 \\
\hline & Depth of plough & 2.24 \\
\hline & Leveling & 2.54 \\
\hline \multirow{13}{*}{ Seed and seedlings } & Seed rate per hectare & 1.99 \\
\hline & Depth of planting seedlings & 2.73 \\
\hline & Selection and healthy seed for sowing & 2.76 \\
\hline & Spacing for transplanting & 2.87 \\
\hline & Proper time for seedling preparation & 2.98 \\
\hline & Method of sowing & 3.17 \\
\hline & Prepare the ground for planting seedlings & 3.19 \\
\hline & Optimum time of sowing & 3.21 \\
\hline & Method of seed treatment & 3.31 \\
\hline & Preparation of nursery & 3.54 \\
\hline & Age of the seedlings for transplanting & 3.85 \\
\hline & Collecting of seedlings & 3.86 \\
\hline & Correct way of planting seedlings in the field & 3.88 \\
\hline \multirow{4}{*}{ Water management } & Time and method of irrigation & 1.25 \\
\hline & Critical stage of water requirement & 1.95 \\
\hline & Water level at time of transplanting & 2.10 \\
\hline & Water level in nursery & 2.50 \\
\hline \multirow{7}{*}{ Weed management } & Knowledge of chemical herbicide & 3.18 \\
\hline & Identification of rice weed & 3.30 \\
\hline & Method use and doses of herbicide & 3.38 \\
\hline & Appropriate time for application of herbicide & 3.50 \\
\hline & Knowledge of cultivation and mechanical practices to preventing weeds & 3.61 \\
\hline & Knowledge of preventive culture and mechanical practices & 3.72 \\
\hline & Biological weed control & 3.81 \\
\hline \multirow{5}{*}{ Fertilization } & Use of organic manures with fertilizers & 2.13 \\
\hline & Doses of fertilizers & 2.48 \\
\hline & Time and method of fertilizer's application & 2.72 \\
\hline & Knowledge about the nutrient content of fertilizer & 3.08 \\
\hline & Knowledge of soil testing & 3.19 \\
\hline \multirow{7}{*}{ Disease and pests control } & Identification of pests and their control measures & 2.79 \\
\hline & Selection of appropriate pesticides & 2.91 \\
\hline & Identification of diseases and their control measures & 3.00 \\
\hline & Method of application and doses of pesticides & 3.33 \\
\hline & Identification of effective factors in rice disease spread & 3.65 \\
\hline & Understanding the disease symptoms of rice & 3.76 \\
\hline & Appropriate time for application of pesticides & 3.87 \\
\hline \multirow{5}{*}{ Harvesting and post harvesting } & Time of harvesting & 1.00 \\
\hline & Preparation of grains for storing & 1.50 \\
\hline & Control of pests and rodents under storage condition & 1.71 \\
\hline & Threshing and winnowing & 2.14 \\
\hline & Drying of harvested paddy & 2.70 \\
\hline \multirow{3}{*}{ Marketing } & Appropriate time for marketing & 2.03 \\
\hline & Appropriate method for marketing & 2.17 \\
\hline & Appropriate place for marketing & 2.31 \\
\hline
\end{tabular}

We: Weighted mean, Source: Field Survey Data, 2014

Table 4 Correlation between the socio-economic characteristics and training needs of rice farmers.

\begin{tabular}{l|c}
\hline \multicolumn{1}{c|}{ Ssocio-economic characteristics } & Correlation Coefficient (r) \\
\hline Age & $0.121 \mathrm{~ns}$ \\
Educational attainment & $0.360^{*}$ \\
Area cultivated with rice & $0.225^{*}$ \\
Years of experience in rice cultivation & $-0.247^{*}$ \\
participate in training courses in rice cultivation & $-0.138 \mathrm{~ns}$ \\
annual revenue from rice cultivation & $0.374^{*}$ \\
\hline ns: not significant, *significant at 0.05 level of correlation. Source: Field Survey Data, 2014
\end{tabular}


Table 5 Distribution of respondents according to their characteristics and the need for training with chi square values

\begin{tabular}{|c|c|c|c|c|c|c|c|c|c|c|}
\hline \multirow{2}{*}{\multicolumn{2}{|c|}{ Categories of characteristics }} & \multicolumn{8}{|c|}{ Categories of training needs } & \multirow{3}{*}{ Chi square } \\
\hline & & \multicolumn{2}{|c|}{ Low } & \multicolumn{2}{|c|}{ Medium } & \multicolumn{2}{|c|}{ High } & \multicolumn{2}{|c|}{ Total } & \\
\hline & & $\mathrm{n}$ & $\%$ & $\mathrm{n}$ & $\%$ & $\mathrm{n}$ & $\%$ & $\mathrm{n}$ & $\%$ & \\
\hline \multirow{4}{*}{ Age (years) } & $28-38$ & 5 & 4 & 25 & 20 & 14 & 11.2 & 44 & 35.2 & \multirow{4}{*}{$0.772 \mathrm{~ns}$} \\
\hline & $39-49$ & 6 & 4.8 & 20 & 16 & 16 & 12.8 & 42 & 33.6 & \\
\hline & $50-60$ & 6 & 4.8 & 19 & 15.2 & 14 & 11.2 & 39 & 31.2 & \\
\hline & Total & 17 & 13.6 & 64 & 51.2 & 44 & 35.2 & 125 & 100 & \\
\hline \multirow{4}{*}{$\begin{array}{l}\text { Educational } \\
\text { attainment }\end{array}$} & $<$ Secondary & 10 & 8 & 8 & 6.4 & 4 & 3.2 & 22 & 17.6 & \multirow{4}{*}{$36.22^{*}$} \\
\hline & Secondary & 5 & 4 & 27 & 21.6 & 18 & 14.4 & 50 & 40 & \\
\hline & University & 2 & 1.6 & 29 & 23.2 & 22 & 17.6 & 53 & 42.4 & \\
\hline & Total & 17 & 13.6 & 64 & 51.2 & 44 & 35.2 & 125 & 100 & \\
\hline \multirow{4}{*}{$\begin{array}{l}\text { Area cultivated } \\
\text { with rice (ha) }\end{array}$} & $<6$ & 6 & 4.8 & 11 & 8.8 & 8 & 6.4 & 25 & 20 & \multirow{4}{*}{$12.37^{*}$} \\
\hline & $6-10$ & 5 & 4 & 39 & 31.2 & 16 & 12.8 & 60 & 48 & \\
\hline & $>10$ & 6 & 4.8 & 14 & 11.2 & 20 & 16 & 40 & 32 & \\
\hline & Total & 17 & 13.6 & 64 & 51.2 & 44 & 35.2 & 125 & 100 & \\
\hline \multirow{4}{*}{$\begin{array}{l}\text { Experience in } \\
\text { rice cultivation } \\
\text { (years) }\end{array}$} & $8-18$ & 9 & 7.2 & 15 & 12 & 11 & 8.8 & 35 & 28 & \multirow{4}{*}{$5.455 \mathrm{~ns}$} \\
\hline & $19-29$ & 5 & 4 & 28 & 22.4 & 20 & 16 & 53 & 42.4 & \\
\hline & $30-40$ & 3 & 2.4 & 21 & 16.8 & 13 & 10.4 & 37 & 29.6 & \\
\hline & Total & 17 & 13.6 & 64 & 51.2 & 44 & 35.2 & 125 & 100 & \\
\hline \multirow{4}{*}{$\begin{array}{l}\text { Participate in } \\
\text { training courses }\end{array}$} & Non & - & - & 33 & 26.4 & 35 & 28 & 68 & 54.4 & \multirow{4}{*}{$31.71^{*}$} \\
\hline & $1-2$ & 10 & 8 & 20 & 16 & 8 & 6.4 & 38 & 30.4 & \\
\hline & $3-4$ & 7 & 5.6 & 11 & 8.8 & 1 & 0.8 & 19 & 15.2 & \\
\hline & Total & 17 & 13.6 & 64 & 51.2 & 44 & 35.2 & 125 & 100 & \\
\hline \multirow{4}{*}{$\begin{array}{l}\text { Annual revenue } \\
\text { from rice (1000 } \\
\$)\end{array}$} & $<15$ & 9 & 7.2 & 10 & 8 & 13 & 10.4 & 32 & 25.6 & \multirow{4}{*}{$18.66^{*}$} \\
\hline & $15-25$ & 8 & 6.4 & 22 & 17.6 & 14 & 11.2 & 44 & 35.2 & \\
\hline & $>25$ & - & - & 32 & 25.6 & 17 & 13.6 & 49 & 39.2 & \\
\hline & Total & 17 & 13.6 & 64 & 51.2 & 44 & 35.2 & 125 & 100 & \\
\hline
\end{tabular}

ns: not significant, *significant at 0.05 level of chi-square. Source: Field Survey Data, 2014

\section{Recommendations}

It is also recommended that more studies should be carried out to assess training needs of rice farmers in other provinces or cities, with more aspects and sub-aspect of rice cultivation. In order to enhance the knowledge and skills of rice farmers and maximize the rice farm productivity a strong extension program needs to be implemented with respect of them training needs.

\section{References}

Alarima CI, Kolawole A, Fabusoro E, Ajulo A, Masunaga T, Wakatsuki T. 2011. Knowledge And Training Needs Of Farmers Adopting Sawah Rice Production Technology In Nigeria, Journal of Food, Agriculture \& Environment, 9 (3\&4): $183-188$.

Ansari B. 2006. Reviewing and Identifying the EducationalExtension Needs Of Kiwi Farmers In Mazandaran Province (Tonekabon And Chalus), MS Thesis, Islamic Azad University, Science and Research Branch.

AOAD. 2015. Arab Organization for Agricultural Development, Arab agricultural statistics yearbook - vol. no. (35), Khartoum, Sudan

Bajpai M, Rathore S, Kaur S. 2007. Training Needs of Rice Growers: A Case of Uttarakhand, Indian Res. J. Ext. Edu. 7 (2\&3): 38 - 40.

Benard R, Dull F, Nagalapa H. 2014. Assessment Of Information Needs Of Rice Farmers In Tanzania; A Case Study Of Kilombero District, Morogoro, Library Philosophy and Practice (e-journal). Paper 1071. http://digitalcommons.unl.edu/ libphilprac/1071

Chawang JK, Jha KK. 2010. Training Needs of Paddy Cultivators in Nagaland, Indian Res. J. Ext. Edu. 10 (1): 74 - 77.
Devarani L.2013.Gender-Specefic Perceivedtraining Needsof Farmers In Improved Rice Cultivation Practices, International j.of Exten.Edu.Vol.9: 8 - 14.

Gina F, Madsen O. 2013. Farmers' Education and Farm Productivity. Evidence from Denmark and from Romania, AgroLife Scientific Journal, 2(1): 175 - 180.

Goli M, Langerodi M, Sahbazi I. 2013.Modeling the Educational Needs of the Rice Cultivating Women in Sari, a township of Mazandaran Province, using Borich's Model, Intl J Agri Crop Sci., 6 (10): 583 - 592.

Mundhe F. 2015. Agricultural productivity in India: trends during five year plans, The Business \& Management Review, 5(4): 175-181.

Nahfees AM. 2013. Descriptive Analysis of Paddy Farmers' Information Needs, Proceedings of the Third International Symposium, SEUSL: 6-7 July 2013, Oluvil, Sri Lanka

Nath SK, Chowdhury S. 2010. Participation of Farm Women in Rice Cultivation and Their Training Needs, Indian J. Ext. Edu. 46 (1\&2): 63 - 66.

SCO. 2016. Central Statistical Organization Iraq, Paddy and Sunflower Production for 2015, Baghdad, PP.17.

Tarlera S, María C, Pilar I, Ana F, Guillermina C, Alvaro R. 2016. Yield-scaled global warming potential of two irrigation management systems in a highly productive rice system, Sci. Agric. 73(1): 43-50 .

Tologbonse D, Fashola O, Obadiah M. 2008. Policy Issues in Meeting Rice Farmers Agricultural Information Needs in Niger State, Journal of Agricultural Extension, 12 (2): 84 - 94.

Tsado JH, Olaleya RS, Ajayi OJ, Umar IS, Nadatsu AJ. 2014. Information And Training Sources Used By Rice Farmers In North Central Nigeria , Journal of Agricultural Extension , 18 (2): 185 - 195 . http://www.ajol.info/index.php/jae 